\title{
Efeito de um sistema de liberação controlada de clorexidina para o controle de placa e gengivite
}

\author{
Effect of a control system the chlorhexidine for plaque and gingivitis control
}

Efecto de un sistema de control de la clorhexidina para el control de la placa y la gingivitis

Esdras de Campos França ${ }^{1 *}$, Karina Imaculada Rosa Teixeira ${ }^{1}$, Ricardo Reis Oliveira ${ }^{1}$, Barbara Bianca Machado Soares ${ }^{1}$, Alexandre Fortes Drummond ${ }^{1}$, Maria Esperanza Cortés ${ }^{1}$.

\begin{abstract}
RESUMO
Objetivo: Comparar a efetividade de um novo sistema de liberação controlada de clorexidina na formulação $0,6 \%$ em gel de clorexidina: $\beta$-ciclodextrina com um gel convencional de clorexidina a $0,6 \%$ e tratamento profilático no controle da placa e gengivite em pacientes ortodônticos. Métodos: 29 pacientes do Curso de Especialização em Ortodontia da Faculdade de Odontologia da Universidade Federal de Minas Gerais com diagnóstico de gengivite foram divididos em 3 grupos que receberam uma única aplicação do gel no início da pesquisa: (G1) Gel de clorexidina a 0,6\%, (G2) Gel de clorexidina: $\beta$-ciclodextrina $0,6 \%$ e (G3) tratamento profilático. A atividade de doença periodontal foi determinada através da coleta do índice de sangramento gengival (IS) Ainamo \& Bay e o do índice de placa visível (IPV) Silness e Löe e realizados início da pesquisa (T0), com 15 dias (T15), 30 dias (T30) e 60 dias (T60). Resultados: G1 foi mais eficiente no período de 15 dias e 30 dias que G2 e G3. Conclusão: $O$ uso de uma dose única de clorexidina incluída em beta-ciclodextrina $\mathrm{Cx}: \beta-\mathrm{Cd}$ em gel é eficaz na redução de sinais clínicos de gengivite de pacientes com aparelhagem ortodôntica.
\end{abstract}

Palavras-chave: Clorexidina, Gengivite, Sistemas de liberação de medicamentos.

\begin{abstract}
Objective: To compare the effectiveness of a new chlorhexidine-controlled release system in the $0.6 \%$ formulation in chlorhexidine gel: $\beta$-cyclodextrin with a conventional $0.6 \%$ chlorhexidine gel and prophylactic treatment to control plaque and gingivitis in patients orthodontic. Methods: 29 patients from the Specialization Course in Orthodontics, Faculty of Dentistry, Federal University of Minas Gerais diagnosed with gingivitis were divided into 3 groups that received a single application of the gel at the beginning of the research: (G1) chlorhexidine Gel at 0, 6\%, (G2) Chlorhexidine gel: $0.6 \% \beta$-cyclodextrin and (G3) prophylactic treatment. The activity of periodontal disease was determined through the collection of the gingival bleeding index (IS) Ainamo \& Bay and the visible plaque index (IPV) Silness and Löe and performed the beginning of the research (T0), with 15 days (T15), 30 days (T30) and 60 days (T60). Results: G1 was more efficient in the period of 15 days and 30 days than G2 and G3. Conclusion: The use of a single dose of chlorhexidine included in beta-cyclodextrin $\mathrm{Cx}$ : $\beta$-Cd gel is effective in reducing clinical signs of gingivitis in patients with orthodontic appliances.
\end{abstract}

Keywords: Chlorhexidine, Gingivitis, Drug delivery systems.

\section{RESUMEN}

Objetivo: Comparar la eficacia de un nuevo sistema de liberación controlada de clorhexidina en la formulación al $0,6 \%$ en gel de clorhexidina: $\beta$-ciclodextrina con un gel convencional de clorhexidina al $0,6 \%$ y tratamiento profiláctico para el control de placa y gingivitis en pacientes ortodónticos. Métodos: 29 pacientes del Curso de Especialización en Ortodoncia, Facultad de Odontología, Universidad Federal de Minas Gerais diagnosticados de gingivitis fueron divididos en 3 grupos que recibieron una sola aplicación del gel al inicio de la investigación: (G1) Gel de clorhexidina al 0,6\%, (G2) Gel de clorhexidina: 0,6\% de $\beta$ -

1 Universidade Federal de Minas Gerais (UFMG), Belo Horizonte - MG. *E-mail: esdrasodonto@gmail.com 
ciclodextrina y tratamiento profiláctico (G3). La actividad de la enfermedad periodontal se determinó mediante la recolección del índice de sangrado gingival (IS) Ainamo \& Bay y el índice de placa visible (IPV) Silness y Löe y se realizó el inicio de la investigación (T0), con 15 días (T15), 30 días (T30) y 60 días (T60). Resultados: G1 fue más eficiente en el período de 15 días y 30 días que G2 y G3. Conclusión: El uso de una dosis única de clorhexidina incluida en el gel de beta-ciclodextrina $\mathrm{Cx}$ : $\beta$-Cd es eficaz para reducir los signos clínicos de gingivitis en pacientes con aparatos de ortodoncia.

Palabras clave: Clorhexidina, Gingivitis, Sistemas de liberación de medicamentos.

\section{INTRODUÇÃO}

A Ortodontia é área da odontologia voltada para supervisão, orientação e correção das alterações que envolvem as estruturas dentárias e faciais (PROFFIT WR et al., 2021). Para a correção das más oclusões, os ortodontistas necessitam utilizar diferentes tipos de aparelhos fixos e/ou removíveis que podem favorecer o acúmulo de placa bacteriana. Vários estudos têm demonstrado que os acessórios ortodônticos adaptados às coroas dentárias dificultam a manutenção da higiene oral. Isso ocorre devido ao aumento significativo de superfícies retentivas, favorecendo o acúmulo do biofilme bacteriano. Cria-se assim, um desequilíbrio na microflora local contribuindo para o desenvolvimento de lesões de mancha branca e alterações periodontais (TÜRKKAHRAMAN H et al., 2005; JORDAN C e LEBLANC DJ, 2002).

Estudos clínicos têm demonstrado que um aumento de placa bacteriana associada ao sangramento à sondagem, podem ser observados durante o tratamento ortodôntico com aparelho fixo. É importante ressaltar que, a responsabilidade na prática da ortodontia compreende não somente a correção das más oclusões, mas também a manutenção da saúde bucal, e em muitos pacientes que fazem uso de aparelhos ortodônticos fixos, observa-se que o controle efetivo da placa dentária, através de métodos mecânicos sofre algumas limitações. Dessa forma, o importante papel dos agentes químicos, na melhora da saúde bucal, deve ser considerado ao se observar casos específicos (GARIB DG et al., 1997).

A Clorexidina ( $\mathrm{Cx}$ ) é um agente químico de alta efetividade no controle da biomassa dental. A forma mais comum comercialmente utilizada dessa droga é a solução de digluconato a $0,12 \%$. Contudo, para a cavidade bucal, o uso de soluções oferece efeitos passageiros, especialmente provocados pela renovação constante da saliva e do muco. Somado a isso, seu uso prolongado e constante provoca alguns efeitos colaterais como manchas escuras nos dentes e perda de paladar (NETUSCHIL L et al., 2003).

Esse fato remete à busca de alternativas para a utilização da clorexidina, a fim de que se obtenham resultados sem efeitos colaterais. Visando melhorar as propriedades físico-químicas e/ou biológicas da clorexidina estão sendo desenvolvidos os complexos de inclusão com ciclodextrinas (Cd). Os complexos supramoleculares formados pela interação entre a clorexidina e a $\beta$-ciclodextrina $(\beta$-cd) apresentam grande potencial para o controle químico do biofilme bacteriano em concentrações menores que aquelas já usadas em soluções, bochechos e géis de clorexidina pura (CORTÉS ME et al., 2001).

Fármacos dentro da cavidade da $\beta$-ciclodextrina estão mais protegidos da desestabilidade química e da degradação por hidrólise quando formam o complexo de inclusão (LOFTSSON T e MASSON M, 2001). Como resultado destas associações, obtém-se um aumento na atividade, solubilidade e seletividade das drogas, ao passo que se reduzem os efeitos adversos (UEKAMA K et al., 1998).

O Objetivo deste estudo foi comparar a efetividade de um novo sistema de liberação controlada de clorexidina na formulação $0,6 \%$ em gel de clorexidina: $\beta$-ciclodextrina com um gel convencional de clorexidina a $0,6 \%$ e tratamento profilático no controle da placa e gengivite em pacientes ortodônticos.

\section{MÉTODOS}

Este estudo clínico controlado, randomizado e cego foi conduzido, de acordo com os princípios descritos na Declaração de Helsinki para experimentos envolvendo seres humanos, após sua aprovação no Comitê de Ética para pesquisas em humanos da Universidade Federal de Minas Gerais (CAAE: 48127415.3.0000.5149). 
Vinte e nove pacientes com idade entre 12 e 17 anos apresentando diagnóstico de gengivite e sob tratamento com aparelho ortodôntico fixo corretivo constituído por bráquetes metálicos Straight-Wire fixados em ambas as arcadas dentárias por um período mínimo de seis meses foram selecionados.

Como critério de inclusão foi considerado: tratamento com aparatologia fixa sem extrações dentárias por um período mínimo de seis meses, nenhum tratamento periodontal cirúrgico prévio, não fumantes, não gestantes, nenhum tratamento com bochecho de clorexidina $0,12 \%$ ou outro agente químico, ausência de Candidose, ausência de reações alérgicas aos componentes dos géis, ausência de terapia medicamentosa nos últimos seis meses.

Os pacientes submeteram-se ao controle de placa, realizado com polimento coronário com pasta de pedra pomes e água com uso de escova de Robson obtendo-se um índice de placa menor que 20\%, e receberam orientações verbais e por escrito para não alterarem o seu padrão de higienização.

A preparação dos compostos de inclusão clorexidina: $\beta$-ciclodextrina foi feita pelo método de liofilização (Labconco $($ ) na proporção $1: 1 \mathrm{com} 0,6 \%$ de cloridrato de clorexidina. Para a confecção do gel foram utilizados os seguintes reagentes: propilenoglicol (15\%); hidroximetil propil celulose (3\%); água destilada $(79,48)$; metil parabeno $(0,15 \%)$, composto de inclusão $(1,77 \%)$, clorexidina $(0,6 \%)$.

A manipulação dos géis empregados neste estudo foi realizada por um farmacêutico devidamente treinado. O gel de clorexidina a 0,6\% (G1) e o gel de clorexidina: $\beta$-ciclodextrina 0,6\% (G2) foram incluídos em seringas separadas por duas cores distintas reveladas após o término da pesquisa. A aplicação dos compostos foi realizada através de moldeiras nos dentes superiores por 4 minutos no início da pesquisa, um grupo de pacientes não recebeu a aplicação de gel.

As medidas clínicas foram realizadas em 4 sítios (vestibular, lingual, mesial e distal) por dente em cada paciente exceto incisivos, caninos e terceiros molares segundo os seguintes parâmetros clínicos: Índice de sangramento a sondagem (IS) (AINAMO J E BAY I,1975) e índice de placa visível (IPV) (LÖE H, 1967).

Para todas as avaliações, utilizou-se a sonda periodontal Goldman Fox/Williams (Trinity ${ }^{\circledR}$, São Paulo, Brasil). Os exames eram realizados nos seguintes intervalos de tempo: início da pesquisa (T0), 15 dias após a primeira aplicação (T15), 30 dias após a primeira aplicação (T30), 60 dias após a primeira aplicação (T60). Dados clínicos foram obtidos de 4 sítios por dente em cada indivíduo em quatro tempos. A média desses dados foi calculada para cada indivíduo e para cada grupo separadamente.

A significância das mudanças nos dados clínicos ao longo do tempo foi determinada usando o teste "friedman" (ANOVA) em cada grupo clínico separadamente. Todas as variáveis correspondentes para cada modelo foram selecionadas para a entrada na regressão logística e foram retidas nos modelos se valores de $p$ significativos $(p<0,05)$ eram obtidos. Para todos os testes foi adotado o nível de significância de $5 \%$.

\section{RESULTADOS}

Um total de de vinte e nove (29) pacientes selecionados para este estudo (Figura 1). Doze (12) eram homens e dezessete (17) mulheres, com idade variando entre 12 e 17 anos. Três (3) indivíduos iniciaram, mas não concluíram o estudo por motivo de falta às sessões de atendimento, dois (1) indivíduos removeram o aparelho fixo durante a pesquisa e foram excluídos dos resultados, mas continuaram o tratamento com os fármacos, quatorze (14) indivíduos não preenchiam os critérios de inclusão.

Nenhum paciente abandonou o tratamento seja por efeitos colaterais ou qualquer manifestação alérgica causada pelo fármaco testado. Os géis de Clorexidina e Clorexidina: $\beta$-ciclodextrina $0,6 \%$ foram capazes de reduzir os índices de placa visível (IPV) e sangramento gengival (IS) por até 30 dias quando comparados a pacientes submetidos apenas a remoção mecânica da placa dental (Tabelas 1 e 2).

Os valores médios dos índices de placa visível de indivíduos após tratamento com clorexidina $0,6 \%$, clorexidina: $\beta$-ciclodextrina $0,6 \%$ e profilaxia após $0,15,30$ e 60 dias. Os dados da observação inicial $T=0$ mostram que todos os pacientes apresentam índices de placa que variam de 0,74 a 0,91 sem diferença estatística entre os grupos (Tabela 1). 
$\mathrm{Na}$ avaliação após 15 dias observamos que os tratamentos com clorexidina $0,6 \%$ e clorexidina: $\beta$ ciclodextrina $0,6 \%$ apresentaram resultados de IPV mais favoráveis quando comparadas à remoção mecânica de placa. Entretanto quando comparamos clorexidina e clorexidina: $\beta$-ciclodextrina não existe diferença estatística entre os mesmos.

Os resultados de IPV após 30 dias de aplicação do tratamento evidenciam que ainda prevalecem os resultados favoráveis dos grupos clorexidina $0,6 \%$ e clorexidina: $\beta$-ciclodextrina $0,6 \%$ em relação à remoção mecânica de placa, também não se observa diferença estatística entre os mesmos. Após 60 dias de aplicação dos sistemas testados foram feitas medidas para exame final deste estudo.

Observou-se que de uma forma geral os índices de placa visível encontrados se aproximaram dos índices iniciais. Sendo que o grupo clorexidina: $\beta$-ciclodextrina $0,6 \%$, neste caso apresentou resultados mais satisfatórios $0,70( \pm 0.26)$ quando comparados a clorexidina e ao grupo que recebeu profilaxia, que apresentou os índices mais elevados.

Os resultados de índice de sangramento (IS) após tratamento de pacientes com géis de clorexidina $0,6 \%$, Clorexidina: $\beta$-ciclodextrina $0,6 \%$ e profilaxia durante os períodos de $0,15,30$ e 60 dias. Inicialmente, todos os pacientes selecionados apresentavam sangramento gengival clinicamente considerável, estes índices variaram entre 0,68 e 0,84 (Tabela 2).

Após 15 dias de exposição ao tratamento indicado observamos grande redução no IS nos grupos clorexidina e clorexidina: $\beta$-ciclodextrina quando comparados à remoção mecânica de placa. Quando comparados individualmente clorexidina $0,6 \%$ e clorexidina: $\beta$-ciclodextrina $0,6 \%$ não houve diferença estatística significativa $(p \leq 0,05)$.

Após 30 dias de exposição aos fármacos não se notou diferença no IS quando comparados aos resultados após 15 dias. Os grupos clorexidina $0,6 \%$ e clorexidina: $\beta$-ciclodextrina apresentaram resultados muito semelhantes e sem diferença estatística entre eles, porém houve diferença quando comparados ao grupo onde se empregou a remoção mecânica da placa dental. Na avaliação final do IS após 60 dias observou-se a mesma tendência já observada no IPV, os índices retornam a apresentar valores semelhantes aos iniciais, sem diferença estatística entre os mesmos.

Figura 1 - Fluxograma do Estudo.

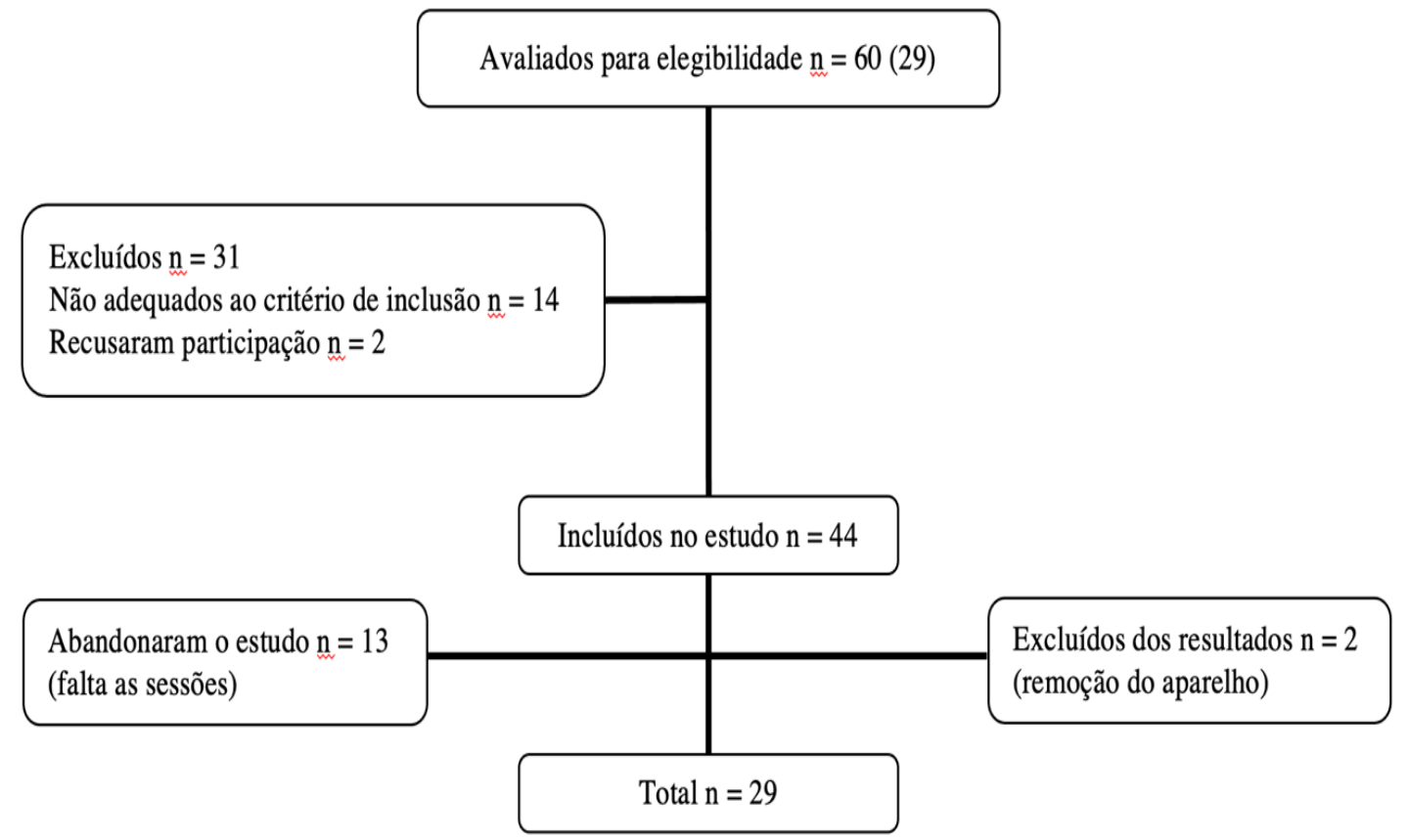

Fonte: França EC, et al., 2021. 
Tabela 1 - Índice de Placa Visível após a aplicação Clorexidina 0,6 \% e Clorexidina: $\beta$-ciclodextrina 0,6 \% e grupo controle com tratamento profilático.

\begin{tabular}{|c|c|c|c|c|c|c|}
\hline Gel & $\mathbf{N}$ & Tempo & Média & SD & $P$ valor & Grupos \\
\hline \multirow{4}{*}{ Controle } & \multirow{4}{*}{11} & T0 & 0.74 & \pm 0.25 & NS & \multirow{4}{*}{ Controle vs $C x$} \\
\hline & & T15 & 0.55 & \pm 0.07 & $<0.05^{\star}$ & \\
\hline & & T30 & 0.56 & \pm 0.02 & NS & \\
\hline & & T60 & 1.00 & \pm 0.27 & NS & \\
\hline \multirow{4}{*}{ Cx: $\beta-c d$} & \multirow{4}{*}{9} & T0 & 0.74 & \pm 0.25 & NS & \multirow{4}{*}{ Controle vs Cx: $\beta-c d$} \\
\hline & & T15 & 0.17 & \pm 0.09 & $<0.001^{*}$ & \\
\hline & & T30 & 0.35 & \pm 0.04 & NS & \\
\hline & & T60 & 0.70 & \pm 0.26 & NS & \\
\hline \multirow{4}{*}{ Cx } & \multirow{4}{*}{10} & T0 & 0.91 & \pm 0.15 & NS & \multirow{4}{*}{$C x: \beta-c d$} \\
\hline & & T15 & 0.15 & \pm 0.06 & NS & \\
\hline & & T30 & 0.37 & \pm 0.07 & NS & \\
\hline & & T60 & 0.97 & \pm 0.15 & NS & \\
\hline
\end{tabular}

Legenda: Teste Friedman (ANOVA) $p \leq 0.05$; ${ }^{*}$ Diferença estatisticamente significante com $p \leq 0.05$; NS: não significante.

Fonte: França EC, et al., 2021.

Tabela 2 - Índice de Sangramento Gengival após a aplicação Clorexidina 0,6 \% e Clorexidina: $\beta$ ciclodextrina $0,6 \%$ e grupo controle com tratamento profilático.

\begin{tabular}{|c|c|c|c|c|c|c|}
\hline Gel & $\mathbf{N}$ & Tempo & Média & SD & $P$ valor & Grupos \\
\hline \multirow{4}{*}{ Controle } & \multirow{4}{*}{11} & TO & 0.84 & \pm 0.22 & NS & \multirow{4}{*}{ Controle vs $C x$} \\
\hline & & T15 & 0.43 & \pm 0.07 & $<0.05^{\star}$ & \\
\hline & & T30 & 0.56 & \pm 0.01 & NS & \\
\hline & & T60 & 0,89 & \pm 0.27 & NS & \\
\hline \multirow{4}{*}{$C x: \beta-c d$} & \multirow{4}{*}{9} & T0 & 0.74 & \pm 0.19 & NS & \multirow{4}{*}{ Controle vs Cx: $\beta-c d$} \\
\hline & & T15 & 0.17 & \pm 0.09 & $<0.001^{*}$ & \\
\hline & & T30 & 0.29 & \pm 0.03 & NS & \\
\hline & & T60 & 0,81 & \pm 0.23 & NS & \\
\hline \multirow{4}{*}{ Cx } & \multirow{4}{*}{10} & T0 & 0.68 & \pm 0.15 & NS & \multirow{4}{*}{$C x: \beta-c d$} \\
\hline & & T15 & 0.16 & \pm 0.07 & NS & \\
\hline & & Т30 & 0.36 & \pm 0.07 & NS & \\
\hline & & T60 & 0.33 & \pm 0.05 & NS & \\
\hline
\end{tabular}

Legenda: Teste Friedman (ANOVA) $p \leq 0.05$; *Diferença estatisticamente significante com $p \leq 0.05$; NS: não significante.

Fonte: França EC, et al., 2021.

\section{DISCUSSÃO}

O desenvolvimento de métodos e fármacos capazes de melhorar as condições de higiene oral tem evoluído consideravelmente nos últimos anos, atualmente os profissionais da área odontológica têm a sua disposição várias alternativas para que seus pacientes sejam instruídos e medicados para melhora das condições de saúde bucal.

Manter um controle correto da placa bacteriana com um periodonto saudável e livre de sangramento não deixa de ser um grande desafio tanto para o cirurgião-dentista como para os seus pacientes, e em se tratando de pacientes ortodônticos o desafio se torna ainda maior pois os aparelhos ortodônticos dificultam a adequadada higienização da cavidade bucal (PACHEVSKA AV, et al., 2019; ROSA EP, et al., 2020; COSTA MR, et al., 2010; OPSAHL VS, et al., 2010). 
Tradicionalmente, o tratamento das periodontopatôgenias começa com as instruções de higiene oral e debridamento não-cirúrgico para remoção do biofilme supra e subgengivais. Isto é seguido por um período de acompanhamento para avaliar a necessidade de tratamento cirúrgico. Quando a doença é controlada, uma terapia de suporte periodontal de 3 a 6 meses de intervalo é recomendada (NEWMAN MG, et al., 2020).

Entretanto, devido a formas mais agressivas de periodontite, formação de biofilme subgengival de difícil controle pela terapia mecânica além das dificuldades em conseguir uma eficiente cooperação dos pacientes, os agentes quimioterápicos podem ser empregados nestes casos quando a terapia mecânica não é suficiente para o controle da doença. Em certas situações, sistemas de liberação localmente controlada de antimicrobianos é aplicado para impedir a progressão da doença (LEBER A, et al., 2018; DRISKO CL, et al., 2005).

O presente estudo abordou inicialmente 60 indivíduos e após a aplicação dos critérios de exclusão foram selecionados 44 voluntários, todos pacientes com aparelhos ortodônticos fixos, entre homens e mulheres com idade variando entre 12 e 17 anos. Dentre os indivíduos examinados para seleção da amostra 100\% deles apresentavam índice de placa e sangramento gengival positivos.

Algumas limitações foram observadas durante a pesquisa como a dificuldade de controlar a adesão dos participantes todas as vezes que foram feitas as rechamadas para avaliação e também o preenchimento a todos os critérios de inclusão.

O emprego da liberação controlada para antibioticoterapia adquire uma conotação maior em função dos grandes problemas causados pela resistência bacteriana. As abordagens quimioterápicas para o tratamento da doença periodontal podem incluir a aplicação tópica de agentes anti-sépticos para liberação controlada de antimicrobianos, como a clorexidina e estes agentes são capazes de aumentar os benefícios obtidos pelo tratamento mecânico convencional e diminuir os efeitos colaterais da clorexidina (MUMMOLO S, et al., 2019; BUCHTER A, et al., 2004; RENVERT S, et al., 2006).

Com base em resultados prévios, que demonstram a atividade antimicrobiana dos sistemas de clorexidina: beta-ciclodextrina em concentrações mais baixas quando comparadas à clorexidina pura neste estudo optou-se por usar uma concentração de 0,6\%(CORTÉS ME, et al, 2001; TEIXEIRA KIR, et al., 2012a; TEIXEIRA KIR, et al., 2012b). A boa atividade antimicrobiana da clorexidina contra um amplo espectro de microrganismos motiva o desenvolvimento de novas formulações para uso clínico que permitam seu uso em baixas concentrações, onde se possa aliar boa atividade, antimicrobiana, baixos efeitos citotóxicos para o organismo e liberação controlada.

Para início do estudo foi realizada a profilaxia, remoção mecânica de placa em todos os indivíduos avaliados independente do grupo ao qual pertenciam. Observamos que após 15 dias da remoção mecânica de placa o grupo controle onde não foi realizada a terapia química já voltava a apresentar índices de placa e sangramento positivos com redução de $23 \%$ para IPV e $40 \%$ para IS após 15 dias. Sendo esta diferença estatisticamente significante. Após 30 dias da terapia mecânica o IPV voltou aos valores iniciais enquanto 0 IS ainda apresentava 19\% abaixo dos valores iniciais. Após 60 dias não havia diferença entre IPV e IS iniciais e os agora observados.

A profilaxia mecânica se mostra como eficaz no controle da placa bacteriana, porém para se ter um bom resultado este método deve ser realizado mensalmente pelo cirurgião dentista (LIMA JE, 2009). Já nos grupos onde além do controle mecânico de placa foi aplicada a terapia química seja com géis de gluconato de clorexidina ou clorexidina: beta-ciclodextrina houve grande redução tantos nos índices de placa quanto de sangramento após 15 dias.

Para o grupo onde foi aplicado gel de clorexidina observou-se uma redução de $77 \%$ no IPV e $60 \%$ no IS após 15 dias de aplicação da terapia. Após 30 dias o IPV ainda apresentava redução de $50 \%$ e IS $32 \%$. Após 60 dias não havia diferença entre IPV e IS iniciais e os agora observados. Estes resultados são pertinentes com a literatura, onde a efetividade de uma solução para bochecho de gluconato de clorexidina 
0,12\% combinado com remoção mecânica de placa em pacientes ortodônticos de 11 a 17 anos de idade com gengivite estabelecida inicialmente, mostraram reduções de $64,9 \%$ do índice de placa e $77,2 \%$ do sangramento gengival após 6 semanas de avaliação (BRIGHTMAN LJ, et al., 1991).

Para o grupo onde foi aplicado gel de clorexidina: beta-ciclodextrina observou-se uma redução de $77 \%$ no IPV e 76\% no IS após 15 dias de aplicação da terapia. Após 30 dias o IPV ainda apresentava redução de $52 \%$ e IS $32 \%$. Após 60 dias ainda se observava redução no IPV de $20 \%$ e IS voltou aos valores iniciais.

O simples fato de os pacientes ortodônticos apresentarem um risco maior para o desenvolvimento de gengivite e visitarem com uma maior frequência o consultório dentário exige que o ortodontista mantenha um rigoroso controle da saúde bucal de seus pacientes (PACHEVSKA AV, et al., 2019).

Após 15 dias da aplicação da terapia mecânica e química não houve diferença estatística entre os grupos gluconato de clorexidina e clorexidina: beta-ciclodextrina. Essas observações podem ser justificadas pela forma de administração do fármaco. A escolha na utilização sob a forma de gel favorece a retenção e adesão nas superfícies da cavidade bucal mantendo o fármaco por mais tempo em contato com as mucosas orais (PEDROSO MAG, 2004). Outra justificativa seria que a própria rede polimérica presente nos géis de hidroxipropil-celulose propicia a liberação mais lenta do fármaco incluído nestas formulações (PEDROSO MAG, 2004).

A liberação de drogas, como clorexidina, meloxicam e indometacina a partir de um filme de acetato de celulose colocadas dentro das bolsas periodontais, estes autores observaram que a clorexidina mesmo sem estar incluída em um sistema de liberação controlada, liberou-se mais lentamente da matriz de acetato de celulose, concluindo que este seria um bom material para liberação lenta de clorexidina em bolsas periodontais (CETIN EO, et al., 2004).

Quando comparamos os resultados de IPV e IS dos mesmos grupos após 30 dias observa-se que existe diferença estatística entre os mesmos. Sendo que, o grupo clorexidina: beta-ciclodextrina apresentou melhores resultados para os índices avaliados após 30 dias do tratamento.

O benefício máximo promovido pelo clorexidina segundo a literatura na redução da placa dentária e gengivite é verificado após 45 dias (YATES R, et al., 1993; JÚNIOR OC, et al., 1996), neste trabalho obtemos resultado semelhante com avaliação após 30 dias, sendo que passados 60 dias os valores de IPV e IS tenderam a voltar aos parâmetros normais dos indivíduos, estes não foram avaliados com 45 dias. Mas cabe observar que para que haja redução do sangramento papilar os bochechos são feitos duas vezes potencializando os efeitos colaterais da clorexidina (JÚNIOR OC, et al.,1996).

Estes resultados corroboram os estudos prévios de nosso grupo que mostram que antimicrobianos incluídos em beta-ciclodextrina apresentaram melhores efeitos que o fármaco livre (CORTÉS ME, et al., 2001; PATARO AL, et al., 2003; TEIXEIRA KIR, et al., 2012a). Outros estudos também demonstraram que sistemas de liberação controlada de antimicrobianos mantêm altas concentrações do fármaco nas bolsas periodontais por 10 dias (GOODSON JM, et al., 1991).

O encapsulamento da clorexidina em ciclodextrina pode levar à mudança em propriedades como: solubilidade, taxa de dissolução, estabilidade e bioavaliabilidade potencializando seus efeitos clínicos. (KAMADA M, et al., 2002).

Após 60 dias da aplicação da terapia mecânica os índices de uma forma geral são semelhantes ou muito próximos aos valores iniciais nos grupos clorexidina e clorexidina: beta-ciclodextrina, não havendo diferença estatística entre estes grupos. Estes achados corroboram a literatura onde a permanência do aparelho ortodôntico por um tempo prolongado favorece os aumentos dos índices de sangramento e bactérias periodontopatogênicas (KOURAKI E, et al., 2005).

Comparando-se os efeitos da terapia mecânica e terapia química seja com gluconato de clorexidina ou clorexidina: beta-ciclodextrina foram estatísticamente diferentes. Sendo que a terapia química apresentou maior redução nos índices avaliados do que a terapia mecânica tradicionalmente empregada em todos os 
períodos de tempo avaliados. Na maior parte dos trabalhos citados suprajacentes é também confirmado que o uso de métodos químicos no controle da placa, principalmente em pacientes pouco colaboradores ou com higiene bucal deficiente, é mais eficiente que o controle mecânico isolado (GARIB DG, et al., 1997; SZULC M, et al., 2018).

O presente estudo também revelou que quando avaliamos o IPV e o IS isoladamente vemos que no grupo onde foi utilizado o gel de clorexidina: $\beta$-ciclodextrina a 0,6 \% ocorreu uma maior redução dos índices do que nos demais grupos avaliados. Ainda é possível notar que somente neste grupo o IPV se mantém significantemente baixo por 30 dias.

Em estudos clínicos semelhantes, a clorexidina isolada tem demonstrado efeitos consideráveis na redução da placa bacteriana, melhorando os índices de saúde oral, é constatado na literatura que a clorexidina a $0,12 \%$ em solução apresenta grande efetividade como agente anti-placa (BORRAJO J, et al., 2002; KEIJSER JAM, et al., 2003) essa concentração de 0,12\% da clorexidina em solução demonstrou ser a mais eficaz, em diversos estudos, para a contenção da placa bacteriana e para o controle da inflamação em doenças bucais. Porém alguns estudos demonstraram que apenas concentrações muito elevadas de $C X$ $(0,2-2 \%)$ apresentam efeito bactericida substancial contra patógenos periodontais (HAYDARI M, et al., 2017).

Algumas observações importantes devem ser feitas quanto a aferição do IPV e do IS: primeiro o IPV retrata uma condição individual e momentânea, podendo variar de acordo com horário e frequência que o paciente faz a higienização bucal no dia da avaliação, diferentemente do IS que acaba sendo um reflexo da higiene bucal com o passar do tempo. Assim estudos de maior duração, no qual o produto em questão é comparado com o controle (positivo ou negativo), ou produtos de placebo e que parâmetros imunológicos e microbiológicos sejam realizados são necessários para estabelecer a real eficácia deste produto e do seu lugar entre os outros agentes utilizados para suporte químico de controle da placa bacteriana.

\section{CONCLUSÃO}

Este estudo demonstrou a eficácia do gel de clorexidina: $\beta$-ciclodextrina a $0,6 \%$ no controle da placa e gengivite em pacientes portadores de aparelho ortodôntico fixo. Para auxiliar na diminuição da quantidade de placa bacteriana evitando tanto a instalação como a progressão de doenças periodontais, o sistema de liberação controlada de clorexidina funciona muito bem como instrumento auxiliar reduzindo o número de aplicações pelos pacientes e profissionais e dessa forma o custo e os efeitos colaterais.

\section{REFERÊNCIAS}

1. AINAMO J, BAY I. Problems and proposals for recording gingivitis and plaque. International Dental Journal, 1975;25:229-35.

2. BORRAJO J, et al. Efficacy of chlorhexidine mouthrinses with and without alcohol: a clinical study. Journal of Periodontology, 2002; 73:317-321.

3. BRIGHTMAN LJ, et al. The effects of a $0,12 \%$ chlorhexidine gluconate mouthrinse on orthodontic patients aged 11 through 17 with estabilished gingivitis. American Journal of Orthodontics and Dentofacial Orthopedics, $1991 ; 100$ (4): 324-29.

4. BUCHTER A, et al. Treatment of severe peri-implant bone loss using autogenous bone and a bioabsorbable polymer that delivered doxycycline (Atridox). British Journal of Oral and Maxillofacial Surgery, 2004; 42: 454-456.

5. CETIN EO, et al. In vitro studies on controlled-release cellulose acetate films for local delivery of chlorhexidine, indomethacin, and meloxicam. Journal of Clinical Periodontology, 2004; 31(12):1117-21.

6. CORTÉS ME, et al. The chlorhexidine: beta-cyclodextrin inclusion compound: preparation, characterization and microbiological evaluation. Journal of Inclusion Phenomena and Macrocyclic Chemistry, 2001; 40: $297-302$.

7. COSTA, M R, et al. Effects of ultrasonic, electric, and manual toothbrushes on subgingival plaque composition in orthodontically banded molars. American Journal of Orthodontics and Dentofacial Orthopedic, 2010;137(2):229-35.

8. DRISKO CL, et al. Evaluation of periodontal treatments using controlled-release tetracycline fibers: clinical response. Journal of periodontology, 1995; 66(8) 692-699.

9. GARIB, DG, et al. Efeito do uso do gluconato de clorexidina e do cloreto de cetilpiridínio, em bochechos, como meio complementar da higiene bucal em pacientes sob tratamento ortodôntico. Ortodontia, 1997; 30(2): 21-30.

10. GOODSON JM, et al. Multicenter evaluation of tetracycline fiber therapy: II. Clinical response. Journal of Periodontal Research. 1991; 26(4): 371-7. 
11. HAYDARI M, et al. Comparing the effect of $0.06 \%-, 0.12 \%$ and $0.2 \%$ Chlorhexidine on plaque, bleeding and side effects in an experimental gingivitis model: a parallel group, double masked randomized clinical trial. BMC Oral Health, 2017;17(1):118.

12. KAMADA M, et al. Cyclodextrin conjugate based controlled release system: repeated and prolonged releases of ketoprofen after oral administration in rats. Journal of Controlled Release, 2002; 82(2-3): 407- 416.

13. JORDAN C, LEBLANC DJ. Influences of orthodontic appliances on oral populations of mutans streptococci. Oral Microbiology and Immunology, 2002; 17(2): 65-71.

14. JÚNIOR OC, et al. Efeitos de bochechos de clorexidina na saúde gengival em pacientes portadores de aparelhos ortodônticos. Periodontia,1996; 5(3): 309-11.

15. KARKHANECHI M, et al. Periodontal status of adult patients treated with fixed buccal appliances and removable aligners over one year of active orthodontic therapy. The Angle Orthodontist, 2013; 83(1): 146-151.

16. KEIJSER JAM, et al. Comparison of 2 commercially available chlorhexidine mouthrinses. Jounal of Periodontology, 2003; 74(2):214-218.

17. KOURAKI E, et al. Gingival enlargement and resolution during and after orthodontic treatment. New York State Dental Journal, 2005; 71(4):34-7.

18. LEBER A, et al. Formulation and Investigation of a Lipid Based Delivery System Containing Antimicrobials for the Treatment of Periodontal Disease. Current Drug Delivery, 2018;15(6):887-897.

19. LIMA JEO. Programa preventivo da cárie dentária baseado no controle mecânico da placa bacteriana em crianças, por meio da profilaxia profissional periódica. Resultados após 25 anos de acompanhamento. Revista Dental Press de Ortodontia e Ortopedia Facial, 2009;14(3): 44-51.

20. LÖE H. The Gingival Index, the Plaque Index and the Retention Index System. Journal of Periodontology, 1967;38(6): Suppl:610-6.

21. LOFTSSON T, MASSON M. Cyclodextrins in topical drug formulations: theory and practice. International Journal of Pharmaceutics, 2001; 225(1-2):15-30.

22. MUMMOLO S, et al. Chlorhexidine gel used as antiseptic in periodontal pockets. Journal of Biological Regulators and Homeostatic Agents, 2019;33(3 Suppl. 1):83-88.

23. NETUSCHIL L, et al. How to select the right mouthrinses in periodontal prevention and therapy. Part I. Test systems and clinical investigations. International journal of dental hygiene, 2003;1(3):143-50.

24. NEWMAN MG, et al. Newman e Carranza - Periodontia Clínica. 13th ed. St. Louis: Elsevier health sciences; 2020 , 1040p.

25. OPSAHL VS, et al. Caries risk and orthodontic treatment. International Orthodontics, 2010; 8(1):28-45.

26. PACHEVSKA AV, et al. Clinical and laboratory assessment the levels of oral hygiene, total protein, hydrogen sulfide and nitrogen metabolites in oral fluid in the development of inflammatory complications during orthodontic treatment of children. Wiadomości lekarskie, 2019;72(5 cz 1):744-747.

27. PATARO AL, et al. Surface effects and desorption of tetracycline supramolecular complex on bovine dentine. Biomaterials, 2003; 24(6):1075-80.

28. PEDROSO, M.A.G. Preparação e avaliação in vitro dos géis de Clorexidina e seus Compostos de Inclusão em beta -ciclodextrina em carboxipolimetileno e hidroxietil celulose, e sua atividade antimicrobiana frente a Streptococcus mutans. [Tese de Doutorado], Faculdade de Odontologia-UFMG, 100p, 2004.

29. PROFFIT WR, et al. Ortodontia Contemporânea. Rio de Janeiro: Editora Guanabara Koogan S.A, 2021. 352p.

30. RENVERT S, et al. Topical minocycline microspheres versus topical chlorhexidine gel as an adjunct to mechanical debridement of incipient peri-implant infections: a randomized clinical trial. Journal of clinical periodontology, 2006 May;33(5):362-9.

31. ROSA EP, et al. Efficacy of photodynamic therapy and periodontal treatment in patients with gingivitis and fixed orthodontic appliances: Protocol of randomized, controlled, double-blind study. Medicine (Baltimore), 2020; 99(14):e19429.

32. SZULC M, et al. Local drug delivery in periodontitis treatment: A review of contemporary literature. Dental and medical problems, 2018; 55(3):333-342.

33. TEIXEIRA KIR, et al. Ultrastructural changes in bacterial membranes induced by nano-assemblies beta- cyclodextrin chlorhexidine: SEM, MFA, and TEM evaluation. Pharmaceutical development and technology, 2013;18(3):600-8.

34. TEIXEIRA KIR. Chlorhexidine: beta-cyclodextrin blocks yeast growth by extraction of ergosterol. Brazilian journal of microbiology, 2012; 43(2):810-8.

35. UEKAMA K, et al. Cyclodextrin drug carrier systems. Chemical reviews., 1998; 98(5): 2045-2076.

36. YATES R, et al. A 6-month home usage trial of a $1 \%$ chlorhexidine toothpaste (1). Effects on plaque, gingivitis, calculus and toothstaining. Journal of clinical periodontology, 1993; 20(2):130-8. 